\title{
The heat increment in fasting sheep of acetic acid partially neutralized with sodium hydroxide
}

\author{
By D. G. ARMSTRONG, K. L. BLAXTER AND N. McC. GRAHAM \\ Hannah Dairy Research Institute, Kirkhill, Ayr
}

(Received 23 Fune, 1960-Revised 29 December 1960)

In previous work Armstrong \& Blaxter (1957) found that when acetic acid was given to fasting sheep as the sole source of energy it was inefficiently utilized in the sparing of body tissues from oxidation. Five experiments gave a mean heat increment of $40.9 \mathrm{kcal} / 100 \mathrm{kcal}$ of acid metabolized, a value which greatly exceeded the heat increments found when propionic or $n$-butyric acids were given. A noticeable feature of the experiments with acetic acid was the marked acidosis that developed when the acid was administered, and it was suggested that the high increments of heat might be associated with accumulation of acid. Respiration-chamber experiments by Møllgaard \& Thorbek (I94I) with milking cows given A.I.V. silage were cited in this regard, for they showed that severe acidosis due to mineral acid increased the heat increment and that neutralization of the acid reduced it.

This paper describes three experiments in which fasting sheep were given acetic acid partially neutralized with sodium hydroxide in an attempt to prevent acidosis; the results are compared with those previously reported when acetic-acid solutions were given. A brief account of some of the findings has been published (Armstrong, Blaxter \& Graham, r958).

\section{EXPERIMENTAL}

Animals. The experimental animals used were three castrated male sheep, $\mathrm{P}, \mathrm{S}$ and $\mathrm{T}$, each with a cannulated rumen. They had been used in the earlier experiments of Armstrong \& Blaxter (1957).

Plan of experiments. Three experiments were carried out, one with each sheep, and all conformed to the same plan. The fasted animal was confined in a respiration chamber and physiological saline $(6.51$./day) was dripped into the rumen at a constant rate by means of the continuous drip-feed pump described by Armstrong \& Blaxter (1957). After 4 days a mixture of acetic acid partially neutralized with sodium hydroxide was added to the saline in sufficient amounts to supply $700 \mathrm{kcal}$ daily and this solution was dripped into the rumen for 3 days. Saline was then given for a further 3 days. The management of the sheep before and after the experiment has been described by Armstrong \& Blaxter (I957).

Solutions of partially neutralized acetic acid. Table I gives details of the solutions infused in the experiments. It will be noted that the amounts of sodium ion in the acid solutions given to sheep $\mathrm{P}$ and sheep T were the same. The amount in the solution infused into sheep $\mathrm{S}$ was appreciably greater. 
i7o D. G. Armstrong, K. L. Blaxter and N. McC. Graham ig6I

Calorimetric and analytical methods. The measurements of oxygen consumption, carbon-dioxide and methane production and of the excretion in the urine of nitrogen, ketones and steam-volatile fatty acids were made at $24 \mathrm{~h}$ intervals. The methods used for these determinations and the procedures for sampling and analysing blood and rumen-liquor samples were those previously described (Armstrong \& Blaxter, I957). The methods used to compute the increments of heat and the intake of metabolizable energy were those described by Armstrong \& Blaxter (I957).

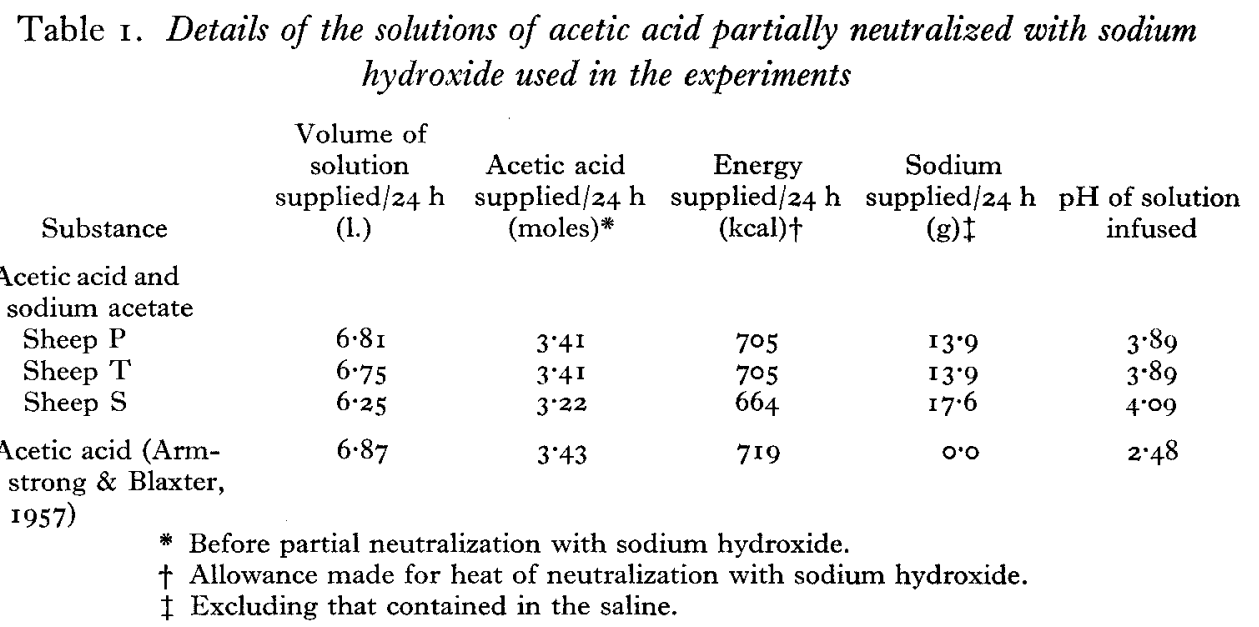

RESULTS

Conditions within the rumen. Table 2 shows the mean changes that occurred in the $\mathrm{pH}$ of the rumen liquor and its content of steam-volatile fatty acids before and during the infusions of the partially neutralized acetic acid or of acetic acid. As would be expected, the introduction of the acid solutions resulted in a considerable depression in $\mathrm{pH}$ and a marked rise in the concentration of steam-volatile fatty acids. With the partially neutralized acid no accumulation of acid occurred in the rumen from the end of the ist to the end of the 3 rd day. The values given in Table 2 show that the $\mathrm{pH}$ of the rumen liquor and its content of steam-volatile fatty acids were both significantly increased.

Composition of the blood. The mean changes in certain of the blood components consequent upon the infusion of the acid solutions are shown in Table 3 . The mean changes in the $\mathrm{CO}_{2}$-combining capacity of the blood plasma showed that no acidosis developed when partially neutralized acetic acid was infused, as judged by the $\mathrm{CO}_{2}$-combining power of the plasma. Apparently no marked alkalosis developed when the infusion was stopped. The effect of the partially neutralized acetic acid on blood sugar concentrations was variable. With sheep $\mathrm{P}$ and sheep $\mathrm{S}$ marked falls occurred, but the values for sheep T tended to remain constant. This variability was reflected in the high standard errors attached to the blood-sugar values. The reason for the lack of fall in the values for sheep $T$ is not known. The ketone concentrations in the blood increased significantly when the partially neutralized solution of acetic acid was infused, and the increases were smaller than when acetic acid was given alone. 


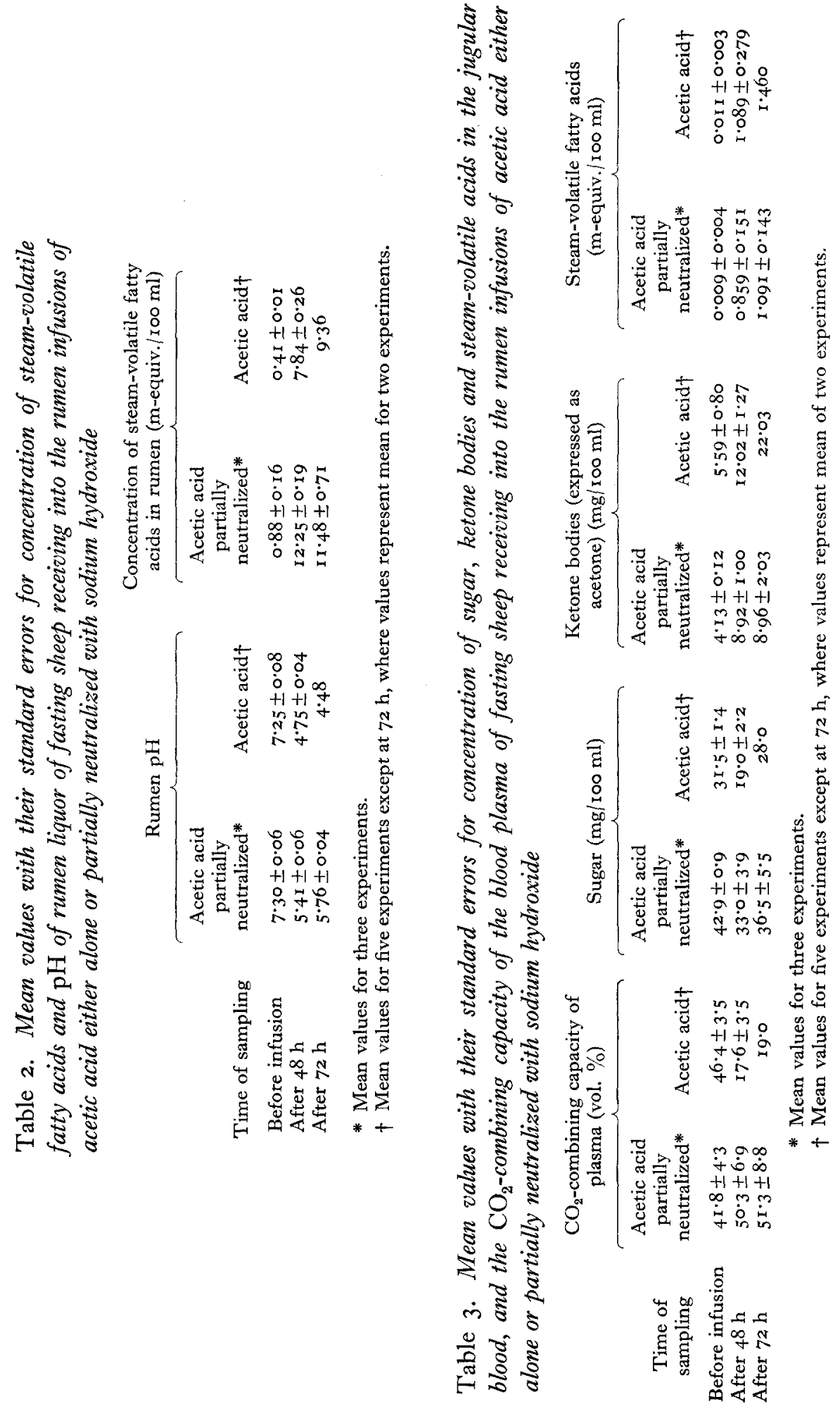


The concentrations of steam-volatile fatty acids in peripheral venous blood rose but there was a tendency for them to be less than when the acetic-acid solution was infused into the rumen.

Composition of the urine. The mean changes in the urinary excretion of nitrogen, ketone bodies and steam-volatile fatty acids, which occurred when the acid was infused, are shown in Table 4. As with acetic acid alone, the partially neutralized acetic acid

Table 4. Mean values with their standard errors for increases in the urinary excretion of nitrogen, ketone bodies and steam-volatile fatty acids by fasting sheep receiving into the rumen infusions of acetic acid either alone or partially neutralized with sodium hydroxide

Substance excreted in urine

Nitrogen $(\mathrm{g} / 24 \mathrm{~h})$

Ketone bodies ( $\mathrm{g}$ acetone/ $24 \mathrm{~h}$ )

Steam-volatile fatty acids (m-equiv./100 ml urine)
Acetic acid partially neutralized*

Acetic acid $\uparrow$

$0.49 \pm 0.17$

$4 \cdot 68 \pm 2 \cdot 43$

$0.98 \pm 0.18$

$2 \cdot 57 \pm 0 \cdot 83$

$\mathrm{I} 62 \cdot \mathrm{x} \pm 87 \cdot 2$

$32 \cdot 3 \pm I I \cdot I$

* Mean values for three experiments during the last $48 \mathrm{~h}$ of infusion.

$\dagger$ Mean values for two experiments during the last $48 \mathrm{~h}$ of infusion and three experiments for last $24 \mathrm{~h}$ of infusion.

Table 5. Mean heat increments of sheep $P, T$ and $S$ when receiving into the rumen infusions of acetic acid partially neutralized with sodium hydroxide and calculation of heat increments as a percentage of the acetic acid metabolized

(Values for final $48 \mathrm{~h}$ of infusion)

Mean increase in heat production ( $\mathrm{kcal} / 24 \mathrm{~h})$

Calorific value of acetic acid infused $(\mathrm{kcal} / 24 \mathrm{~h})$

Correction:

Tissue accumulation of fatty acid $(\mathrm{kcal} / 24 \mathrm{~h})$

Tissue accumulation of ketone bodies $(\mathrm{kcal} / 24 \mathrm{~h})$

Urinary excretion of fatty acid (kcal/24 h)

Unoxidized urine ketone bodies (kcal/24 h)

Calorific value of acetic acid metabolized (kcal/24 h)

Heat increment as percentage of acetic acid meta-

bolized

$\begin{array}{ccc}\text { Sheep P } & \text { Sheep T } & \text { Sheep S } \\ 248 & 258 & 283 \\ 705 & 705 & 664 \\ 30 \cdot 3 & 39 \cdot 4 & 18 \cdot 9 \\ 2.5 & -3 \cdot 9 & 7 \cdot 3 \\ 52 \cdot 7 & 28 \cdot 8 & 18 \cdot 8 \\ 54.2 & 33.6 & 17 \cdot 0 \\ 565.3 & 607 \cdot 1 & 602 \cdot 0 \\ 43.9 & 42.5 & 47 \cdot 0\end{array}$

Table 6. Heat increments (kcal/10o kcal acid metabolized) of sheep $P, T$ and $S$ when receiving into the rumen infusions of acetic acid or acetic acid partially neutralized with sodium hydroxide

$\begin{array}{ccl}\text { Acetic acid } \\ \text { partially } \\ \text { Sheep } & 43 \cdot 9 & \text { Acetic acid } \\ \mathrm{P} & 42 \cdot 5 & 4 \mathrm{I} \cdot \mathrm{I} \dagger \\ \mathrm{T} & 47^{\circ} \mathrm{O} & 32 \cdot 5 \dagger, 42 \cdot 8 \\ \mathrm{~S} & 44^{\circ} 5 \pm \mathrm{I} \cdot 3 & 46 \cdot \mathrm{I} \dagger, 39 \cdot 5 \\ \text { Mean value with its } & 40 \cdot 9 \pm \mathrm{I} \cdot 8\end{array}$

* Values computed in Table 5 .

+ Values computed from measurements made in final $36 \mathrm{~h}$ of a $48 \mathrm{~h}$ experiment. All other values computed from measurements made in final $48 \mathrm{~h}$ of a $72 \mathrm{~h}$ experiment. 
resulted in a significant increase in the excretion of all three constituents. The presence of sodium ions in the rumen infusion did not affect significantly the excretion of nitrogen or ketone bodies, but resulted in a greater loss of steam-volatile acid in the urine.

Increments of heat. The heat increments obtained in each experiment with partially neutralized acetic acid are shown in Table 5, and in Table 6 these values are compared with those obtained for acetic acid given alone. From the mean values shown in Table 6 it is clear that the prevention of acidosis did not result in a significant change in the heat increment of acetic acid when metabolized by fasting sheep.

\section{DISCUSSION}

When acetic acid partially neutralized with sodium hydroxide was given to sheep, the concentration of acid in the rumen liquor rose to a significantly higher level than it did when the acid alone was given. During the last 2 days of the acid infusion the mean $\mathrm{pH}$ of the rumen liquor from the sheep receiving partially neutralized acetic acid was $5^{\cdot 6}$ and from sheep receiving acetic acid $4 \cdot 6$. From the mean values for $\mathrm{pH}$ and for concentration of steam-volatile fatty acids in rumen liquor at 48 and $72 \mathrm{~h}$ given in Table 2, approximate mean concentrations of acetate anion and of undissociated acid can be calculated. When partially neutralized acetic acid was infused the acetate concentration was about $0.10 \mathrm{M}$ and the undissociated acid concentration $0.0 \mathrm{I}$; when acetic acid was infused the concentrations were about 0.04 and $0.05 \mathrm{M}$, respectively. If it is assumed that there is no effect of duration of infusion or experimental treatment on the volume of rumen liquor, then once an equilibrium was established the net absorption of total acid (as anion plus undissociated acid) would be the same with both treatments. The higher level of total steam-volatile fatty acid present in the rumen liquor when the $\mathrm{pH}$ was 5.6 suggests differential rates of absorption of acetic-acid anion and of undissociated acid.

Briggs, Hogan \& Reid (1957) have shown that, with the exception of diets with which considerable quantities of lactic acid are produced, the $\mathrm{pH}$ of the rumen is largely a function of volatile fatty-acid concentration in the rumen. With the exception of rumen liquor from sheep on diets producing lactic acid, any deviations from a close relationship between $\mathrm{pH}$ and concentration of volatile fatty acids are attributed by these workers to varying rates of salivary excretion and in some instances to the presence of high concentrations of ammonia. The fact that the concentration of volatile fatty acids in the rumen liquor is elevated in the presence of sodium ions suggests that saliva affects the relationship by reducing hydrogen-ion concentration, and thus altering the equilibrium levels of undissociated fatty acid and of fatty-acid anions within the rumen. Our findings provide at least a partial explanation of the results of Cason, Ruby \& Stallcup (1954) who showed that, in steers given a variety of diets, rumen $\mathrm{pH}$ was more closely related to the ash content of the ingesta than to the content of steam-volatile fatty acids in the rumen liquor.

When infused into the rumens of fasting sheep, acetic acid induced a marked fall in the concentration of sugar in blood (Armstrong \& Blaxter, 1957). In the experi- 
i74 D. G. Armstrong, K. L. Blaxter and N. McC. Graham ig6i

ments reported here, in which sufficient alkali was present to prevent the development of a marked acidosis the same was true for two sheep, but in the third there was no fall in blood-sugar concentration. The reason for this apparent anomaly was not discovered. In this regard Kronfeld (1957) found an increase in blood glucose content in sheep after acetate infusion, but Lipsky, Alper, Rubini, Van Eck \& Gordon (I954) found no significant changes in blood glucose content in normal human subjects after the administration of sodium acetate.

Evidence is available that blood sugar content varies depending upon the degree of acidosis. Thus Kronfeld, Campbell, Hooper \& Galligan (I959) showed that in fasting sheep receiving infusions of butyric acid into the blood or rumen the acidosis which occurred was accompanied by a fall in blood glucose content. When, however, sodium butyrate was infused by either route, the resulting alkalosis was accompanied by an increase in blood glucose concentration. These workers postulated that a glycogenic effect of $n$-butyric acid is blocked by the acidosis. As Phillipson \& Cuthbertson (1956) have pointed out, it is not possible to say from such experiments whether the increased blood sugar content reflects a synthesis of glucose from the metabolite infused. Only experiments with labelled substrates can provide the answer. In this respect, it is of interest to note that from experiments with ${ }^{\mathrm{I}}-{ }^{14} \mathrm{C}$ sodium butyrate, Ash, Pennington \& Reid (1959) concluded that the rise in blood-sugar content in sheep produced by the infusion of butyric acid is not due to formation of sugar directly from the acid.

Armstrong \& Blaxter (1957) put forward two possible explanations for the high heat losses associated with the metabolism of acetic acid when given as the sole source of energy to fasting sheep. The first was that an alternative metabolic pathway for the complete dissimilation of acetic acid to carbon dioxide and water exists in which the efficiency of free-energy capture is considerably less than in oxidation through the tricarboxylic-acid cycle. The second was that the accumulation of acetic acid and the metabolic acidosis which occurs are responsible. Spontaneous hydrolysis of the pyrophosphate bond of adenosine triphosphate was suggested as a way in which this might occur. The experiments reported here suggest that the accumulation of hydrogen ions due to acidosis is not responsible Whether future work will reveal that the first explanation is also not tenable, and that the reason for the high heat increment of acetic acid when given to fasting sheep lies elsewhere, remains to be seen.

\section{SUMMARY}

I. Three experiments have been carried out in which three sheep with rumen fistulas each received into the rumen an infusion of acetic acid partially neutralized with sodium hydroxide. The infusion mixture supplied about $700 \mathrm{kcal} / 24 \mathrm{~h}$. The results have been compared with the results of five experiments (Armstrong \& Blaxter, r957) in which sheep received infusions of acetic acid under similar conditions.

2. Infusion of the partially neutralized acetic acid resulted in a smaller decrease in rumen $\mathrm{pH}$ and a higher content of steam-volatile fatty acid in the rumen liquor than when equivalent amounts of the unneutralized acid were given. 
3. The presence of the sodium ion in the infusion mixture prevented the development of an acidosis as measured by the $\mathrm{CO}_{2}$-combining capacity of the plasma. Significant increases in the concentrations of ketone bodies and of steam-volatile fatty acids in the blood were still observed. The amounts of nitrogen, ketone bodies and steam-volatile fatty acids excreted in the urine were also significantly raised by the infusion of partially neutralized acetic acid.

4. The increment of heat was computed from oxygen consumption and $\mathrm{N}$ metabolism and found to be $44 \cdot 5 \pm \mathrm{I} \cdot 3 \mathrm{kcal} / \mathrm{I} 00 \mathrm{kcal}$ partially neutralized acid metabolized. This value did not differ significantly from that obtained with acetic-acid infusions, namely $40 \cdot 9 \pm \mathrm{r} \cdot 8 \mathrm{kcal} / \mathrm{I} 00 \mathrm{kcal}$ acid metabolized.

We thank Mr D. Paterson and Mr D. MacSporran for the day-to-day care of the sheep and for help with the respiration apparatus, and also Miss J. Muir and Miss E. Bryce for analytical work.

\section{REFERENCES}

Armstrong, D. G. \& Blaxter, K. L. (1957). Brit. F. Nutr. II, 247.

Armstrong, D. G., Blaxter, K. L. \& Graham, N. McC. (1958). Proc. Nutr. Soc. r7, xxxii.

Ash, R. W., Pennington, R. J. \& Reid, R. S. (1959). Biochem. $\mathcal{F} .7 \mathbf{~}, 9 P$.

Briggs, P. K., Hogan, J. P. \& Reid, R. L. (1957). Aust. F. agric. Res. 8, 674.

Cason, J. L., Ruby, E. S. \& Stallcup, O. T. (1954). F. Nutr. 52, 457.

Kronfeld, D. S. (1957). Aust. F. exp. Biol. med. Sci. 35, 257.

Kronfeld, D. S., Campbell, L. A., Hooper, L. L. \& Galligan, S. J. (1959). Amer. F. vet. Res. 20, 430. Lipsky, S. R., Alper, B. J., Rubini, M. E., Van Eck, W. G. \& Grordon, M. E. ( 1954). F. clin. Invest. 33, I 296.

Møllgaard, H. \& Thorbek, G. (1941). Beretn. Forsegslab. Kbh. no. 196.

Phillipson, A. T. \& Cuthbertson, D. P. (1956). Int. Congr. Anim. Hust. vir. Madrid, 6, 50. 